\title{
Sinifying Joyce: Appraising Second-Language Confucian Readers' Constructions of Meaning in Ulysses
}

\author{
C. A. DeCoursey ${ }^{1}$ \\ ${ }^{1}$ Department of English Studies and Translation, American University of Science and Technology, Beirut, \\ Lebanon \\ Correspondence: C. A. DeCoursey, Chair, Department of English Studies and Translation, American University \\ of Science and Technology, Ashrafieh, Beirut, Lebanon. E-mail: cdecoursey@aust.edu.lb
}

Received: March 6, 2015 Accepted: April 26, 2015 Online Published: August 31, 2015

doi:10.5539/ells.v5n3p76 URL: http://dx.doi.org/10.5539/ells.v5n3p76

\begin{abstract}
This paper explores how Chinese students construct the meaning of Joyce's Ulysses. Second-language learners are known to use reading strategies with difficult texts such as Ulysses. This study of 157 undergraduate Chinese nonspecialists who read parts of Ulysses in an English literature general education course explores how Confucian values shape Chinese readers' responses to Ulysses, in both reading strategies and content areas. Survey data was collected using a 4-point Likert scale. Qualitative data was gathered using six appraisal terms. Student reflections were analysed using Corpus Tool. Results indicate the primacy of culture in shaping individual readings. Second-language learners use metacritical reading strategies in making sense of this difficult text. However, the inclusion of culturally challenging material, and complex interiority and narrative moved these proficient second-language readers beyond their usual concerns with accuracy of translation and synthetic overviews of complex plot and character detail, towards literary reading. The challenges of Ulysses as a text induced appreciation of unreliability in narration, postmodern theories of meaning, and the disjunctures and discontinuities of the self, expressed in interior monologues, and disqualified in the social performance of identity.
\end{abstract}

Keywords: appraisal analysis, Confucian values, general education, James Joyce, second-language reading

\section{Introduction}

At the 2013, $10^{\text {th }}$ annual Shanghai Book Fair, an "extravagant marketing campaign" produced "giant billboards in downtown areas in major cities across China", drawing more than a thousand people to buy Ulysses (China Weekly, 2013). A middle school student said, "When my father brought that book home, it gave me a reading experience I had never had before." (China Weekly, 2013) Shanghai People's Publishing House editor Wang Weisong noted at the James Joyce lecture, "In cities like Beijing, Shanghai, Shenzhen and Chongqing, serious literature has always had readers obsessed by reading and able to digest classics of western literature." (China Weekly, 2013) Given the sheer number of non-native readers of English literature in China, Chinese readers will soon be a significant proportion of Joyce readers. We may wonder, how do Chinese readers construct the meaning of a text like Ulysses?

Until recently, the meaning of literary texts has rested with native speakers. With the number of English readers worldwide approaching 2 billion, English has become a global language, deterritorialised and transnational, belonging to no single people or culture (Davies, 2002). The global status of the language impact shows its literature is read (McArthur, 2004). There are about 350 million English users in China alone (Mair, 2003). About $11 \%$ of the 1.3 billion Chinese population are tertiary graduates (Graddol, 2008). Chinese universities have adopted a General Education model, using English literary texts to scaffold English language and culture learning (Wang, 2006). Chinese institutions emphasise the teaching of classic over popular works (Chen, 2006). Joyce's literary works, including Ulysses, are often taught.

Scholars have reasons to be interested in Chinese reception of canonical English literature. Chinese graduates contribute disproportionately to the global knowledge economy, forecast to comprise $20 \%$ of global graduates by 2020 (Unesco Institute for Statistics, 2008). English has become a shared and negotiated space, dominating world discourse but no longer belonging to native speakers (Crystal, 2000). Globalisation has a clear tendency to redefine personal, local and national identities (Banks, 2008). Tertiary students share aspects of a transnational 
identity (Levitt, 2001). Reading English literature is a part of this identity (Walther, 2009). The number of global Second-language (L2) readers of English literature will re-shape the commonly received meanings of literary masterpieces (Kroskrity, 2000). Reading the readers is one means of finding out what texts mean, in their new, global contexts (DeCoursey, 2012).

Readers construct the meaning of literary texts in the act of reading (Cambourne, 2002). Ulysses offers numerous opportunities for acts of interpretive construction (Meyer, 2003). Proficient tertiary L2 readers, now the majority of readers of English literature in the world, are more adept than native-speaker readers at metacritical reading strategies. These are the linguistic competencies required to decode texts, and to interpret the cultural codes involved in constructing the meaning of texts (Ruddell \& Unrau, 2004). Ulysses is notoriously complex stylistically, and has also drawn criticism on moral grounds. Among specialists, there are few texts with a more powerful claim to be called masterpiece. But these same issues are variously handled in different cultures, making Ulysses a prime candidate to be struck off the reading lists of undergraduate nonspecialists worldwide. This could remove a brilliant text from global English-language curricula, and in time, from global discussion. Thus, it is important to explore whether Ulysses is viable with L2 readers.

This study appraised Chinese readers' responses to Ulysses, taught as part of a nonspecialist general education (Gen Ed) literature subject taught at a Hong Kong university. In China, as in the west, reading literature in the Gen Ed classroom entails multiple learning objectives including the appreciation of high-culture icons, and delivery of competencies in reading and writing, ethics, civics and intercultural sensitivity (Blattner \& Frazier, 2004). In ESL contexts, reading literary texts is felt to assist in naturalising idiomatic language, and teaching target-language culture performance (Walther, 2009). Difficult texts challenge students to read beyond the sentence and paragraph level, introducing them to issues of stylistics and intertextuality (Showalter, 2003). Ulysses raises social issues for students to reflect on: gender roles and relations, interiority, sexuality, racism, the canon and its challengers, modernism and postmodernism, structure and post-structuralism (Khatib \& Rezaei, 2011; McKormick \& Shofner, 2012).

There are specific challenges involved in teaching Ulysses in a Chinese context, including the cultural and lexicogrammatical difficulty of the text. Reading is more reconstructive and less immersive, in a second language (Pulido, 2003). When reading a culturally difficult text, Chinese readers are known to use comprehension aids, including online searching, the use of dictionaries and translators, and reading online summaries and commentaries (Huang et al., 2009). As Chinese has no tense, voice or number, reading literary English often becomes an act of back-translating (Ji et al., 2004). Where westerners read English phonologically through the ear, decoding graphemes and phonemes to reconstruct meaning, Chinese read through the eye, taking in whole-word units where each character represents a word and idea (Chan \& Siegel, 2001). Chinese tertiary students value accuracy over narrative fluency, emotional immediacy or cultural understanding, in constructing translated meaning (Cheng, 2000). This will work against the development of literary reading. Translating a text that is as dense with literary, historical, cultural and linguistic references, allusions and puns as Ulysses cannot be fully successful. In such cases, Chinese students may react negatively, feeling they cannot gain a clear understanding of the text's meaning.

For Chinese readers, Ulysses may also suffer from its communist-era reputation. While Hong Kong is a former British colony, the population is $10 \%$ mainlander (Hong Kong Census, 2007). Many Hong Kong Cantonese-speakers have Putonghua-speaking parents or grandparents (Li \& Bray, 2007). When reading difficult texts, Chinese readers seek translations (Upton \& Lee-Thompson, 2001). But translations of Ulysses in China prior to the 1960s were condemned as obscene and nihilist, and liberal humanist traditions of reading were rejected as elitist (Jin, 2001). While there was greater critical openness in the mainland from the 1970s, still, discussions of Joyce remained among scholars, in universities and the diaspora, allowing negative perspectives to persist. Complete translations of Ulysses were only available from 1993 (Tsoi, 2007). Thus, students searching for Chinese-language aids to Ulyssesare likely to find some that characterise the text negatively.

Readers achieve meaning by applying their cultural values to texts (Smagorinsky, 2001). Chinese readers use Confucian values in constructing the meaning of Ulysses. Confucian Heritage Cultures (CHC) have been extensively researched (Yao, 2000). Key elements include the view that social stability requires hierarchy, and family is the model for all social organisations. Solidarity is important, meaning family members choose cooperation over individuality and collectivity over independence (Bian et al., 2002). Virtue is defined in relation to task fulfillment, not the inner self (Rawwas et al., 2007). Expression of emotion is discouraged (Chen et al., 2005). Long-term orientation and harmony are integrating values for processes of self- and social regulation ( $\mathrm{Li}$, 2002). Within the family, children experience group membership over individuality (Rao, 2002). Primary responsibility is to parents before any love relationship (Nguyen et al., 2005). Parents and children both are 
obligated in the performance of virtue, the primary constituent of lian (脸 or 臉, face) (Lam et al., 2002). The child is obligated to study, being expected to reflect deeply for character development, and study persistently to gain employment for family support (Watkins \& Biggs, 2001; Cheng, 2002). For Chinese students, English is connected to future employment (Fu \& Chiu, 2007). They expect that rewards will be gained only after lengthy investment of time and effort (Siu, 2003). Chinese culture avoids direct criticism, preferring an indirect or culturally polite style which employs hedges and mixes positive with negative comments (Wei \& Lei, 2011). Chinese students reproduce Confucian rhetorical strategies, when writing in English (Panetta, 2001). We may anticipate that Chinese readers will express these values and strategies, inresponding to Ulysses.

Research questions addressed in this study include, how do Chinese readers construct the meaning of Ulysses? How do they respond to the lexical, grammatical and cultural difficulties of this text? How do Confucian values impact the meanings these readers construct?

\section{Method}

There were 157 undergraduate participants in this study. All were native Cantonese or Putonghua speakers proficient in English to the level of IELTS 6 required for English medium-of-instruction university entrance. None were English majors. All were registered in a Gen Ed English literature course. Quantitative and qualitative data was taken over two consecutive years. A four-stage process was used: (i) questionnaire development, (ii) instructional period, and (iii) quantitative data collection and (iv) qualitative data collection. The questionnaire used a 4 point Likert scale where 1 was "not at all", 2 was "a little", 3 was "some" and 4 was "a lot". Attitudinal questions used six terms, two reflecting Affect, two reflecting Judgment, and two reflecting Appreciation (Gehm \& Scherer, 1998). The terms "interesting" and "likable" checked participants" positive or negative sense of satisfaction and happiness after studying Ulysses. The terms "easy" and "appropriate" checked participants' positive or negative sense of the lexicogrammatical and cultural difficulty of the text. The terms "attractive" and "worthwhile" checked participants" reaction to and sense of the value of reading Ulysses. English sentences eliciting quantitative data were brief and syntactically simple, through the repeated use of "In my opinion, reading Ulysses was...", focusing attention on the attitudinal element of the prompt sentence (Block, 1998). The survey was piloted with a group of 38 English majors, resulting in enhanced visual clarity and simplified instructions.

During the instructional period, class content was organized so that texts read earlier supported those read later in the semester. Participants read translated sections from Homer's Odyssey in weeks 2 and 3, Hamlet in weeks 4 and 5, selections from Dubliners and Portrait of the Artist as a Young Man in weeks 6 and 7, and then Episode 1 "Telemachus" and Episode 15 "Circe", from Ulysses, in weeks 8 and 9. These Episodes contain themes which intersect with Confucian values. After the readings, participants were asked to fill out a survey in class, and write a brief (100 word) personal reflection. Reflections elicit more subjective content than formal academic genres such as essays do (Bloch, 2007). As the same task was given for all literary works read for this subject, students were accustomed to giving their opinions.

Appraisal analysis was used to analyse student responses. An outgrowth of Systemic Functional Linguistics, Appraisal taxonomises the lexicogrammar realizing subjective personal opinions (Scherer, Schoor, \& Johnstone, 2001). When giving an opinion, individuals choose words from the many options available in English (Halliday, 1994; Martin \& White, 2005). Appraisal analysis is widely used in sentiment analysis, mapping choices onto system networks of increasing delicacy (Martin \& Rose, 2003). Appraisal system networks gain validity from the convergence of psychological and linguistic models of emotion (Oatley et al., 2006). Appraisal analyses are routinely used in computational linguistics research (Hood, 2004). This study used CorpusTool (CT) to tag student blogs (O’Donnel, 2008). Machine tagging of evaluative lexicogrammar is widely accepted as reliable (Bednarek, 2009). This method has "gained widespread acceptance in the field of emotion research" (Kuppens, Van Mechelen, Smits, De Boek, \& Ceulemans, 2007, p. 690). In particular, it identifies attitudinal patterns efficiently (Wiebe et al., 2005).

Realisations of subjective attitudes are either negative or positive (Read \& Carroll, 2010). For example, “I didn't enjoy it when Stephen fights with the soldier" is negative, where "I was glad Leopold could finally help out his son" is positive. Attitude may be directly inscribed, as in "It is quite funny when Shakespeare is a character talking to Leopold". It may be indirectly invoked. For example, "Just running away at the end made the play seem less satisfying" disperses the negative attitudes among several lexical and grammatical elements of the sentence (Turney, 2002).

Appraisal systems are articulated into sets and subcategories reflecting the specific English lexis available, as in Figure 1. 


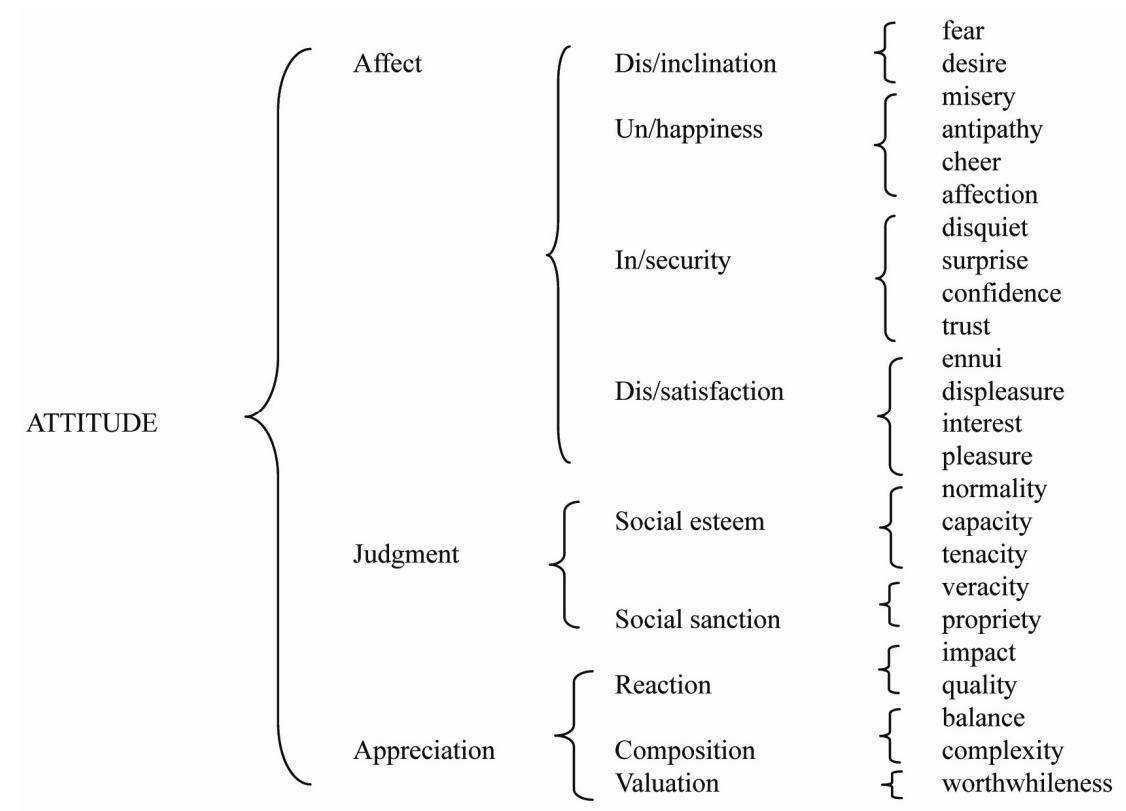

Figure 1. The attitude system

Student texts were uploaded to CT. Attributions were tagged by the researcher, who has training using CT for Appraisal analysis, and separately by a graduate research assistant with coursework in systemic functional linguistics. Both had 100+ hours' experience with attitude-tagging. The researcher and second tagger had first shared a 3-hour norming session analysing participant reflections. After tagging, the inter-rater reliability was calculated using Cohen's $\kappa$ (Lombard, Snyder-Duch, \& Bracken, 2004). The percent-overall value was 0.872, and the free-margin value 0.839 . These values are stronger than would be attributable to chance.

\section{Data}

The quantitative data indicated that students found Ulysses very interesting and quite likable, not easy, and less than averagely appropriate. They found it only a bit more than averagelyattractive, but very worthwhile, as in Table 1.

Table 1. Mean scores for six attitudes towards Ulysses

\begin{tabular}{llll}
\hline Attitudinal term & System network, category-set & mean & $\sigma$ \\
\hline interesting & Affect, satisfaction-interest & 3.50 & 0.18 \\
likable & Affect, un/happiness-happiness & 3.09 & 0.23 \\
easy & Judgment, social esteem-normality & 1.15 & 0.11 \\
appropriate & Judgment,social sanction-propriety & 1.90 & 0.26 \\
attractive & Appreciation, reaction-quality & 2.55 & 0.19 \\
worthwhile & Appreciation, valuation-worthwhileness & 3.40 & 0.12 \\
\hline
\end{tabular}

The Appraisal terms separate elements of participants' emotional responses, distinguishing their feelings of interest which were quite strong, from their finding the work attractive for which the mean is only above average. Similarly, adjudication of the ease of reading gets the lowest score, but is decoupled from their estimations of the value of reading Ulysses, which was high. Participants' appreciated the value of reading this text, even though they found it not very attractive.

Reflections comprised a corpus of 23369 words. In all, 1046 attitudes were realised, of which $487=46.55 \%$ were negative and 559=53.44\%positive. Attitudinal density was 44.76 per 1000 words. For both negative and positive attitudes, the majority clustered in five frequently-realised categories, as in Table 2. 
Table 2. Frequently-realised attitudes about Ulysses

\begin{tabular}{|c|c|c|c|c|c|c|c|c|}
\hline rank & negative & & & & positive & & & \\
\hline & system & set & category & $\%$ & system & set & category & $\%$ \\
\hline 1 & Judgment & social sanction & propriety & 15.48 & Appreciation & valuation & worthwhileness & 16.28 \\
\hline 2 & Appreciation & reaction & quality & 14.44 & Affect & dis/satisfaction & interest & 15.56 \\
\hline 3 & Appreciation & composition & complexity & 12.94 & Appreciation & composition & complexity & 12.16 \\
\hline 4 & Judgment & social esteem & normality & 8.83 & Judgment & social esteem & normality & 9.30 \\
\hline \multirow[t]{2}{*}{5} & Appreciation & reaction & impact & 6.78 & Appreciation & reaction & quality & 7.33 \\
\hline & & & & 58.47 & & & & 60.63 \\
\hline
\end{tabular}

The high negative value should not be taken as an indicator of students' dislike of the text. The balanced negative-positive polarity of the corpus likely reflects the Confucian cultural tendency tomix evaluative terms. For example, participants most frequently expressed the positive view that it was worthwhile ( 91 realisations) to read Ulysses, andnearly as often also held the view that the text contained socially improper content (74 realisations). These Judgments of social sanction mainly touched on matters of social normativity.

\section{Discussion}

Several patterns can be seen in this data. First, a common attitudinal mix was "interesting" ( 87 realisations) with "quality" (69 realisations). Given that Chinese culture discourages expressions of emotion, the frequency of interest indicates a strong positive response. Aggregating positive realisations of interest ("interesting", "fascinating") with negative realisations of ennui ("not boring", "not dull") yields 108 realisations, the most-frequently realised subjective response, and the only frequently-realised emotion. Second, participants responded nearly equally negatively ( 68 realisations) and positively (63 realisations) to the complexity of the text, with both often realised in the same reflection $(103=65.61 \%)$. Participants responded more positively to the canonical status of Ulysses (Judgment, social esteem-normality, 52 realisations), than negatively to its unconventional content (43 realisations). They responded more positively to the stylistic qualities of the text (41 realisations) than negatively to its impact on them personally (33 realisations). That is, students found Ulysses interesting, worthwhile, improper, difficult, complicated in a bad way, complicated in a good way, famous but peculiar, of good quality but having a bad emotional impact on the reader. This is quite a nuanced response.

Confucian cultural values were realised in the qualitative data, for example the Confucian tendency to use mixed and hedged evaluations:

1) Interesting and demanding.

2) Interesting. It will be very challenging to read the whole book.

3) It's so intriguing. So many semiotic meanings maybe help us learn culture and some new words.

4) Complex, and it provides us the opportunity to access the unusual modern literature.

5) Lots of literary allusions I don't know. Thought-provoking.

Example 1 is a simple combination of positive and negative terms. Example 2 implies a negative evaluation; "challenging" graded up in "very" suggests the task may be too difficult. In Example 3, the positive "intriguing" is hedged by "maybe", implying doubtthat readers could use Ulysses to learn English culture and vocabulary. Example 4 uses mixed terms which can be either positive or negative, "complex" and "unusual". Example 5 politely applies the negative judgment to the student, and realises a mildly positive attitude for the text.

Similar Confucian values and rhetorical strategies were realised in responding to the text's cultural and psychological content.

6) Maybe it has a lot of content, and therefore can be elaborated. The dark settings, characters, themes, it is too difficult for me. I do not think the story should be end with the fight and the vision of the dead child.

7) Such a different background. It has the cultural background we're not so familiar with. Too difficult to organize the scene and the characters in my mind. The thinking is so confused.

8) Seldom a book depicts the dreams and psychology of characters as the skeleton of the book. Too various personalities, so hard to follow. Scattered, I do not know when it is inside Leopold's mind and when it is in the house. It is too different to understand. The way of writing the story is interesting. 
These examples place a hedge ("maybe", "seldom") or weak positive ("different") before a negative realisation, as a way of responding to the bar episode, the number and diversity of characters, and the difficulty of following the switches between interior monologue and exterior happenings.

However, participants responded to positively to the use of other languages, which engaged theirL2 skills and identity. In all, $106=67.52 \%$ participants commented on the multilinguality of the text, most $(91=57.96 \%)$ positively reflecting awareness of their second-language readers' status and skills:

9) There are difference languages involved. It means the Europe readers will need to know foreign languages.

10) I like the foreign languages. But its languages are so difficult.

11) The multilingual will be a problem for readers not knowing the other languages.

12) Seeing the languages is interesting. I am excited to know that the native-speakers are doing so.

Many ( $86=54.78 \%)$ invoked their status and experience as L2 readers:

13) The language is strange but interesting. It takes a long time to read a small episode.

14) My vocabulary is too limited to read it well. There are too many odd, difficult vocabulary.

15) Too complex to read clearly. Complicated vocabulary, and characters. Usually we like to read something simpler for comprehending the content. This story cannot be understood quickly.

16) There are many words about religion and Europe. The lexis are way too difficult. It requires much effort and plenty of time to read it. Maybe people will not like it because too abstract and complex ideas for general readers.

17) It is very difficult due to foreign language and many slangs and unusual vocabularies. I am spending all day before comprehending just the story about Stephen's fears about his friend.

18) I like it because very challenging language. It contains some colloquial words. I spend much time to look them up. I don't know why Stephen talks that way, even he fears that Mulligan won't respect his apartment.

Examples 13 and 14 identify vocabulary as the major challenge. Examples 15 and 16 connect vocabulary to characters and themes, noticing how this complexifies the challenge of reading. Examples 17 and 18 itemise kinds of difficult vocabulary, and their relationship to building understanding of characters' personal and emotional situations.

Many $(96=61.15 \%)$ noted their use of aids and explanatory apparati:

19) It is hardly comprehensible to me and I have read many novels. I find it in translated version first.

20) It's hard to manage the reading because you need to write down too many details, just like the book. How to arrange the different characters? If there are lots of people, it's hard to coordinate and organize reading it.

21) Usually we have notes and tables. The teacher needs to make it simple and easy to understand or students cannot read it due to the problems with the language. We cannot gain the meaning.

22) Reading this book is a problem due to many characters, some imaginary, very complex characters. I need to find excellent guide to reading this book.

23) There will be some hard words even for the person who gets the text in translation. You have to revise the text a lot. It needs a very experienced reader. The readers may find it hard if it is not presented well with background informations, and also the thoughts and dreams need to be dealt with.

These examples section the second-language reader's process of constructing a literary reading into stages of native- and L2 reading, followed by revision focused on systematising characters and details, in order to produce meaning. They reflect Confucian long-term orientation, with gains achieved after investment of time and effort. They construe Confucian social hierarchy, where the student devotes extensive effort, and expects the teacher to provide detailed guidance. They show a naive belief in authorial intention, a view of reading, readers, texts and teachers discordant with Ulysses and out of step with contemporary understanding. These indicate the challenge, but also the value of communicating what and how Ulysses means, to global L2 readers.

The preceding examples showcase L2 readers' awareness of reading as a set of practices which promote accuracy in the constitution of meaning. But reading Ulysses impelled participants toward perceptions and questions that were literary in nature, including cultural sensitivity and stylistic awareness. In struggling to make sense of Ulysses' disquieting literary maneuvers, and finding that their usual strategies did not serve them well, participants moved beyond their focus on accuracy. For example, when Ulysses made it difficult for them to use 
Confucian values to attribute meaning to the text, many $(81=51.59 \%)$ noted that their attempts to locate the meaning of Ulysses in its connection to its classical source failed:

24) Many problems, settings, character, conversations. Maybe it relates to some adventure Odyssey had. We should read this deeply, to gain the meaning.

25) This is the literature based on the classic of Odyssey. This is a very famous work by the great author. It's a classic work. It is really worth as well as difficult.

26) It's hard to understand the classic literary, but it's worth trying. We can also read the Odyssey story about going home to wife and son. It should help to show the story of Leopold and Stephen.

27) It is connected with Odyssey, touching the core issues of humanity like family, wife and husband, home. It is so complicated! And has many unfamiliar people!

28) If it can connect with Odyssey closely, it is a modern version of Odyssey. But I need good luck, to see the stages in Stephen and Leopold becoming reunification after many separation.

Examples 24 and 25 merely point to the Odyssey as a potential means of sourcing the meaning of Ulysses, and examples 26 and 27 assert that the virtuous family ambitions of the Odyssey's main characters supply the meaning for the struggles of characters in Ulysses, but cannot specify how this works. Example 28 uses "reunification", a term resonant with complex positive and negative meanings in the Hong Kong context. This lexical choice cannot be accidental. This is placed alongside realisations of doubt, via the counterfactual, about the connection between the texts ("if it can connect") and the constructive effort ("I need good luck to see"). Overall, participants had expected Ulysses to convey reliable metanarrative meaning via complex systematised detail. When it did not, they began perceiving that literary meaning could undermine their expectations about the nature of meaning itself.

Ulysses required participants to read beyond the sentence and paragraph levels, and to construct meaning on the basis of stylistics and intertextuality. In particular, three elements of Ulysses drew participants away from naive and towards sophisticated perceptions of literary meanings: its interior monologues, its portrayal of unconventional family relationships, and its sexual content. Reading the interior monologues focuses attention on the psychology of the characters, to which the language is a disorderly guide. Second-language readers must therefore decide how to bridge the gap between accurate lexical translation, and meaning.

29) The text language is the one in Leopold's mind. Very complicated. I cannot take the meaning easily. It is hard to get consensus about so many characters, what did James mean. I read on the internet that even many foreigner does not know what James means. I think I cannot read it. It requires so many actions and stages, so many characters and scenes and long conversations and sometimes not real. It requires a rich imagination to read it successfully.

30) It's crucial James must control the changes, from characters, and from when we are in Leopold's mind and when we are in a hallucination. Or the reader cannot understand. Even we use the online summaries and translations, maybe we cannot do it. James is brave. You have to be brave to reveal the inside of the mind of the down people.This is what James wants us to know.

31) I am just beginning to understand Stephen and then we change to Leopold. How can we follow Leopold's mind? James should pay more attention to the readers feeling. Characters are getting on and off the stage all times and it is very difficult to control. Why James does this? He wants the confusion to be the symbol of the way of our life. Everything is happening to us.

32) It contains some lifelike scenarios. You need to pay attention to every gesture and expression Leopold makes, and the words are too complicated to make the character understood. This may allow more vivid impression to the reader. But it cannot clarify when Leopold is only inside his thoughts, and when he is talking to Stephen. I think James does not want to clarify.

Example 29 acknowledges that, due to the interior monologues, the text cannot be treated schematically, but requires imagination to understand. Example 30 positively adjudicates literary writing about characters and experiences beneath the epic register, asserting this as the author's intended meaning. Example 31 negatively evaluates the difficulties of following Leopold's reveries, but positively appreciates this as desirable for literary purposes, and valuable for readers who experience similar confusions. Similarly, example 32 negatively adjudicates the challenge of interpreting texts and characters through linguistic and gestural codes, but positively adjudicates the unclarity, or indeterminacy of meaning, suggesting that this is desired and realistic ("lifelike"). In order to comment on the issue of interior monologues, participants posited an implied author, his purposeful 
function in "control[ling] the changes" in order to create literary meaning, and his relationship with the implied reader. This has moved them into literary reading.

The family themes in Ulysses made participant self-aware of their use of Confucian values in constructing meaning. Confucian values privilege the family as a locus of organisation and obligation, where the performance of virtue is expected. Ulysses offers many challenges to this view. Few participants $(11=7.01 \%)$ simply reproduced Confucian values and found no merit in Joyce's portrayal of family:

33) It's a new version of Odysseus but can't really find the focus of the characters. James does not really make Stephen as Telemachus, or Leopold as Odysseus. Penelope should be more in the book. James is like the old style. But every character shares the same focus on psychological description! I mean greedy, not giving help to the family, so they are unhappy and they get ill.

Many $(78=49.68 \%)$ expressed both conventional Confucian views along with perceptions of value in Ulysses' unconventional family:

34) Leopold helped Stephen when he argued the police officer. They should not go to the tavern, but this story shows the life of the family in the poor streets.

35) The first service is always to help the family member. Even if what was recorded is the hard money life and will not be brought back to the family, Leopold cares the security of the family.

36) The dark of human nature is universal to cultures. Chinese literature seldom explores this area. The red street district is similar with our Chinese culture. Chinese literature has complex plots but not a lot of strong characters or sexual indications. Maybe Chinese will like it. It is bold, but interesting.

37) Leopold takes Stephen to the brothel. For the westerner maybe this is a kind of experience. For Chinese culture, he will not be a good father. But James wants to show the real imperfect life. Good theme of psychology and dreaming. Except he writes the dream story, we cannot feel it like a dream. I like to, but it needs too long for me to take his meaning.

Examples 34 and 35 offer a meliorist Confucian reading, censuring but excusing characters on diegetic grounds. Example 36 acknowledges the legitimacy of discussing sexualities, comparing Chinese and western literary traditions, and hedging ("Maybe") but positively realising ("bold, but interesting") an implied Chinese reader's stance. Example 37 accepts literary depictions of negative interiority. Despite persistent doubts about the difficulties of the text, these readers havegained experience in literary reading. Where negative realisations focused on Leopold's failure at Confucian-fatherly moral guidance, positive realisations relativised reading with Confuciancultural commitments, and found value in western values and stylistics. While these readers still conflateauthor, implied author, narrator(s) and readers, they have perceived and valued Joyce's narrative techniques, and managed multiple interpretive frames for literary reception.

The Confucian sense of obligation to family restricts youthful love relationships. In responding to the sexualities involved in Episode 15, few (13=8.28\%) were critical:

38) Leopold is not a good father except he stops Stephen giving the excess money. But Leopold takes him to the prostitute. Such people in Chinese society too, but we do not write it in a book.

Many more ( $48=30.57 \%$ ) comments showed interest in exploring these traditionally regulated issues.

39) It seems this drama occurs in Leopold's mind as well as in the dirty streets. I like it a little. This style of literature is very different from the Chinese ones, too much sexual innuendo. Explicit sex scenes are different to Chinese culture. I don't think people like it. If my friend wants to read it I will say please never think about that. Students will read the sophisticated texts which are good depending on how much work.

40) Some people will like this book. It is well similar to Chinese culture because Chinese society is being dirty also. But it is well different. Brothels in China were less filthy places. Chinese are romantic-minded! This kind of adult story is not that popular in China. I think weare interested to see the unusual story.

41) The seduction is similar to Chinese society. This is more straightforward. Chinese authors for lust and caution have done it more carefully. Chinese literature is much more indirect. It is like the Chinese opera "Golden Horny Girl". It is much more irrational in the story by James. It is very interesting to see the realistic situation with alcohol and hallucination.

42) It is similar to Chinese book 'Dream of Red Chamber". But James has too many lines which are dirt. Chinese culture is more traditional. To some extent, I definitely like it. It is considered as one of masterpiece so some want to try it. I think Chinese readers maybe interested, but not really like it. This is 
not good for kids. But for university students it helps to talk about the reality.

Example 39 sanitizes Ulysses' sexual content by downgrading some of it as fantasy. It quarantines the novel's social impact by distinguishing groups who are less or more able to read such literary works, placing students in the class of sophisticates. But it fails to perceive sexuality as an essential quality of the text, or relativise the readers' own Confucian values. Example 40 acknowledges differences of cultural styles, prefers Chinese romance, but also positively realises liking and interest in the sexual content. Example 41 also acknowledges cultural styles, realising interest in the socially less-acceptable content. The comparison with the many popular operas based on the Chinese classic "Dream of the Red Chamber" (红楼梦 or 紅樓夢), an $18^{\text {th }}$-century novel with multiple characters involved in various sexual relationships, connects sexuality in literature with Chinese literary traditions, positioning the student as well-disposed to trying sophisticated texts, but also placing him within the collectivity of "Chinese readers", on whose behalf he expresses doubt about whether they will evaluate Ulysses positively. Example 42 also constructs classes of readers, but legitimises the reader in finding value in Ulysses. This reader realizes liking (emotion), and frames not-liking as the adjudications of others, meanwhile appreciating utility in reading this normally regulated content.

\section{Conclusion}

This study has explored how Ulysses is read by Confucian readers, and how its popular reception may be impacted by the status of English as a global second language. Reading Ulysses now occurs in contexts where most students are reading in their L2, and have both local and transnational identities. This study has shown the value of reading the readers: their encounters with this rich, complex text show how Gen Ed programs and tertiary institutions worldwide may understand the significance of reading difficult texts. A text like Ulysses might easily collect negative reviews, from students and teachers alike. Yet we have seen that the fairly balanced polarity of attitudes (46.55\% negative, $53.44 \%$ positive) reflects Confucian rhetorical strategies, and the frequently-realised attitudes are in fact nuanced: these readers found Ulysses interesting, worthwhile, improper, difficult, complicated in a bad way, complicated in a good way, famous but peculiar, of good quality but having a bad impact.

This study has produced three main results. While one cannot easily generalise to 1.3 billion people, and a substantial diaspora, from a mere sample, still it is useful to read these readers, as Chinese readers are now a substantial portion of the world's non-native readers of English literature, and of university student bodies worldwide. This study shows that globalisation and the loss of native-speaker control over literary meaning offers opportunities for English literature as a field. Now that the English language and by extension its literary masterpieces belong to a global readership, not any specific geography, culture or heritage, the act of reading literary icons has been valorised among non-native speakers. As an attendee at the Shanghai Book Fair Joyce lecture noted, "Chinese people are becoming interested in more diverse aspects of the western world, even in those that the westerners themselves have not noticed" (China Weekly, 2013). Such opportunities are viable for the most challenging of English-language literary masterpieces.

Second, reading the readers has shown the extent, and the limits, of the interpretive tools L2 students employ as part of their L2 and cultural identities. The quantitative data showed that Chinese readers viewed Ulysses as very interesting (3.50), quite likeable (3.09), not at all easy (1.15) or appropriate (1.90), but more than a little attractive (2.55) and very worthwhile (3.40). The qualitative data indicated that these L2 readers were positive about linguistic features of Ulysses that cause difficulty for western students. This feature was a positively-reviewed attraction for non-native speakers, particularly the inclusion of foreign-language and obscure lexis which engaged second-language readers' literacy skills, and levelled the playing field with native speakers somewhat. This is consonant with the frequency of realisation of interest in the Appraisal data. The clarity of this result is more significant given the Confucian cultural tendency to discourage expression of emotion, and the Confucian rhetorical strategy to avoid strong polarity in making adjudications and appreciations. Second-language readers can make good use of their metacritical skills in reading Ulysses.

Most significant was the ability of Ulysses to move readers beyond L2 diligence. Comments showed that the value to nonspecialist L2 readers of reading Ulysses lay in offering them a way into literary perceptions, in areas such as unreliability in narration, postmodern theories of meaning, and appreciating the psychology of self via the disjunctures and discontinuities between interior monologues and the social performance of identity. We cannot expect literary reading to be achieved in a single Gen Ed course. But the data suggests that encountering Ulysses was able to move most L2 undergraduate readers beyond a reading focused on accuracy of translation and synthesis of detail, into the encounter with imagining and interpreting characters, and considering their views about the nature of meaning. It had the ability to make readers aware of, and relativise, their own cultural 
commitments. Despite Ulysses containing content which directly contravenes these readers' cultural conventions, still it was able to draw them into finding value in non-normative forms of narration and conventionally inappropriate content. Here, we see the value to tertiary nonspecialists of reading a text like Ulysses, including exposure to forms of writing and meaning which do not fit simplistic or schematic approaches.

\section{References}

Anon. (2013, August 17). Reading less, some Chinese still love Jams Joyce. China Weekly. Retrieved from news.xinhuanet.com/english/china/2013-08/17/c_132638303.htm

Banks, J. A. (2008). Diversity, group identity, and citizenship education in a global age. Educational Researcher, 37(3), 129-139. http://dx.doi.org/10.3102/0013189X08317501

Bednarek, M. (2009a). Polyphony in Appraisal: Typological and topological perspectives. Linguistics and the Human Sciences, 3(2), 107-136.

Bian, Y., Tu, E., \& So, A. (Eds.). (2001). Survey Research in Chinese Societies: Methods and Findings. Hong Kong: Oxford University Press. http://dx.doi.org/10.3102/0013189X08317501

Blattner, N. H., \& Frazier, C. L. (2004). Assessing General Education Core Objectives. Assessment Update, 16(4), 4-6.

Bloch, J. (2007). Abdullah's blogging: A generation 1.5 student enters the blogosphere. Language Learning and Technology, 11(2), 128-141. Retrieved from http://ltt.msu.edu/vol11num2/bloch/default.html

Block, D. (1998). Exploring interpretations of questionnaire items. System, 26(3), 403-425. http://dx.doi.org/10.1016/S0346-251X(98)00022-0

Cambourne, B. (2002). Holistic, Integrated Approaches to Reading and Language Arts Instruction: The Constructivist Framework of an Instructional Theory. In A. E. Farstrup \& S. Samuels (Eds.), What Research Has to Say About Reading Instruction (pp. 25-47). Newark, DE: International Reading Association.

Chan, K., \& Siegel, L. (2001). Phonological processing in reading Chinese among normally achieving and poor readers. Journal of Experimental Child Psychology, 80(1), 23-43. http://dx.doi.org/10.1006/jecp.2000.2622

Chen, S., Cheung, F., Bond, M., \& Leung, J. (2005). Decomposing the construct of ambivalence over emotional expression in a Chinese cultural context. European Journal of Personality, 19(3), 185-204. http://dx.doi.org/10.1002/per.538

Chen, X. M. (2006). An analysis of some concepts about general education. Journal of Higher Education.

Cheng, X. (2002). Chinese EFL students' cultures of learning. In C. Lee \& W. Littlewood (Eds.), Culture, Communication and Language Pedagogy (pp. 103-116). Hong Kong: Hong Kong Baptist University Press.

Cheng, X. T. (2000). Asian students' reticence revisited. System, 28(3), 435-446. http://dx.doi.org/10.1016/S0346-251X(00)00015-4

Crystal, D. (2000). Language Death. Cambridge: Cambridge University Press.

Davies, A. (2002). The native speaker: Myth and reality. Clevedon, England: Multilingual Matters.

DeCoursey, C. A. (2012). Reading literature, realising culture: Appraising intercultural attitudes in the Hong Kong classroom. In C. A. DeCoursey (Ed.), Language Arts in Asia: Literature and drama in English, Puronghua and Cantonese. Newcastle Upon Tyne (pp. 50-86). Cambridge Scholars Publishing.

$\mathrm{Fu}$, J., \& Chiu, C. (2007). Local culture's responses to globalization: exemplary persons and their attendant $\begin{array}{lllll}\text { values. Journal of Cross-Cultural } & \text { Psychology, 38(5), }\end{array}$ http://dx.doi.org/10.1177/0022022107305244

Graddol, D. (2008). Why global English may mean the end of 'English as a Foreign Language. ULIS \& British Council, London.

Halliday, M. A. K. (1994). An Introduction to Functional Grammar. London, Edward Arnold.

Hood, S. (2004). Managing attitude in undergraduate academic writing: A focus on the introductions to research reports. In R. Ravelli \& R. Ellis (Eds.), Analysing Academic Writing: Contextualised Frameworks (pp. 24-44). London, Continuum.

Huang, H. C., Chen, C. L., \& Lin, C. C. (2009). EFL learners' use of online reading strategies and comprehension of texts: An exploratory study. Computers and Education, 52(1), 13-26. http://dx.doi.org/10.1016/j.compedu.2008.06.003 
Ji, L. J., Zhang, Z. Y., \& Nisbett, R. (2004). Is it culture or is it language? Examination of language effects in cross-cultural research on categorization. Journal of Personality and Social Psychology, 87(1), 57. $\mathrm{http}: / / \mathrm{dx}$. doi.org/10.1037/0022-3514.87.1.57

Jin, D. (2001). Shamrocks and Chopsticks: James Joyce in China. Hong Kong: City University of Hong Kong Press.

Khatib, M., \& Rezaei, S. (2011). Literature in the EFL/ESL classroom. English Language Teaching, 4(1), 201-208. http://dx.doi.org/10.5539/elt.v4n1p201

Kroskrity, P. (2000). Regimes of Language. Santa Fe NM, School of American Research Press.

Kuppens, P., Van Mechelen, I., Smits, D. J. M., De Boeck, P., \& Ceulemans, E. (2007). Individual differences in patterns of appraisal and anger experience. Cognition and Emotion, 21(4), 689-713. http://dx.doi.org/10.1080/02699930600859219

Lam, C. C., Ho, S. C., \& Wong, N. Y. (2002). Parents' Beliefs and practices in Confucian heritage cultures: The Hong Kong case. Journal of Southeast Asian Education, 3(1), 99-114. Retrieved from http://www.seameo-journal.com/journal/index.php/education/article/view/32/31

Levitt, P. (2001). The transnational villagers. Berkeley, CA: University of California Press.

Li, J. (2002). A cultural model of learning: Chinese 'heart and mind for wanting to learn'. Journal of Cross-Cultural Psychology, 33(3), 248-269.

Li, M., \& Bray, M. (2007). Cross-border flows of students for higher education: push-pull factors and motivations of mainland Chinese students in Hong Kong and Macau. Higher Education, 53(6), 791-818.

Lombard, M., Snyder-Duch, J., \& Bracken, C. C. (2004). Practical Resources for Assessing and Reporting Intercoder Reliability in Content Analysis Research Projects. Retrieved from http://www.temple.edu/sct/mmc/reliability

Mair, C. (Ed.). (2003). The politics of English as a world language: New horizons in postcolonial cultural studies. Amsterdam: Rodopi.

Martin, J. R., \& Rose. (2003). Working with discourse: Meaning beyond the clause (2nd ed.). London, Continuum.

Martin, J. R., \& White, P. (2005). The Language of Evaluation: Appraisal in English. New York, Palgrave.

McArthur, A. (2004). Is it world or international or global English, and does it matter? English Today, 79, 3-15. http://dx.doi.org/10.1017/S0266078404003025

McCormick K., \& Shofner, M. (2012). Here Comes Everybody. Pedagogy, 10(2), 363-388. http://dx.doi.org/10.1215/15314200-2009-043

Meyer, S. (2003). Broadly representative? The MLA's Approaches to Teaching World Literature series. Pedagogy, 3(1), 21-51.

Nguyen, P., Terlouw, C., \& Pilot, A. (2005). Cooperative learning vs Confucian heritage culture's collectivism: Confrontation to reveal some cultural conflicts and mismatch. Asian Education Journal, 3(3), 403-419. http://dx.doi.org/10.1080/14675980500502172

O'Donnell, M. (2008). Demonstration of the UAM CorpusTool for text and image annotation. Proceedings of the ACL-08: HLT Demo Session (Companion Volume, pp. 13-16). Columbus, Ohio, Association for Computational Linguistics.

Oatley, K., Keltner, D., \& Jenkins, J. M. (2006). Understanding Emotions. Blackwell, Oxford.

Panetta, C. (Ed.). (2001). Contrastive rhetoric revisited and refined. Mahwah NJ, Erlbaum.

Pulido, D. (2003). Modeling the role of second language proficiency and topic familiarity in second language incidental vocabulary acquisition through reading. Language Learning, 53(2), 233-284. http://dx.doi.org/10.1111/1467-9922.00217

Rao, Z. (2002). Chinese students' perceptions of communicative and non-communicative activities in the EFL classroom. System, 30(1), 85-105. http://dx.doi.org/10.1016/S0346-251X(01)00050-1

Rawwas, M., Swaidan, Z., \& Izakson, H. (2007). A comparative study of ethical beliefs of master of Business Administration students in the United States with those in Hong Kong. Journal of Education for Business, 82(3), 146-158. http://dx.doi.org/10.3200/JOEB.82.3.146-158 
Read, J., \& Carroll, J. (2010). Annotating expressions of Appraisal in English. Language Resources and Evaluation. http://dx.doi.org/10.1007/s10579-010-9135-7

Ruddell, R., \& Unrau, N. (2004). Theoretical models and processes of reading (5th ed.). Newark, DE: International Reading Association.

Scherer, K. R., Schoor, A., \& Johnstone, T. (Eds.) (2001). Appraisal processes in emotion: Theory, methods, research. Canary: Oxford University Press.

Showalter, E. (2003). Teaching literature. Blackwell, Oxford.

Siu, O. (2003). Job stress and job performance among employees in Hong Kong: The role of Chinese work values and organizational commitment. International Journal of Psychology, 38(6), 337-347. http://dx.doi.org/10.1080/00207590344000024

Smagorinsky, P. (2001). If meaning is constructed, what is it made from? Toward a cultural theory of reading. Review of Educational Research, 71(1), 133-169. http://dx.doi.org/10.3102/00346543071001133

The Hong Kong Government Census Statistical tables, from "Population by Ethnicity". Retrieved from http://www.bycensus2006.gov.hk/data/data3/index.htm

Tsoi, P. (2007). Joyce and China: A mode of intertextuality, the legitimacy of reading and translating Joyce. LEWI Working Paper Series, 61, 1-24. Retrieved from http://www.hkbu.edu.hk/ lewi/pub_work_info.html

Turney, P. D. (2002). Thumbs up or thumbs down? Semantic orientation applied to unsupervised classification of reviews. Proceedings of the $40^{\text {th }}$ annual meeting of the Association for Computational Linguistics. Philadelphia, PA, USA. http://dx.doi.org/10.3115/1073083.1073153

UNESCO Institute for Statistics. (2008). Global education digest 2008: Comparing education statistics across the world. Montreal, UIS.

Upton, T., \& Lee-Thompson, L. C. (2001). The role of the first language in second-language reading. Studies in second-language acquisition, 23(4), 469-496.

Walther, I. (2009). Curricular planning along the fault line between instrumental and academic agendas: A response to the Report of the Modern Language Association on Foreign Languages and Higher Education: New Structures for a Changed World. Teaching German, 42(2), 115-22. http://dx.doi.org/10.1111/j.1756-1221.2009.00045.x

Wang, Y. Q. (2006). General Education and Cultural Attainment Education in the University. Peking University Education Review.

Watkins, D., \& Biggs, J. (Eds.). (2001). Teaching the Chinese Learner: Cultural, psychological and contextual influences. CERC, Hong Kong and ACER Australia.

Wei, Y., \& Lei, L. (2011). Lexical Bundles in the Academic Writing of Advanced Chinese EFL Learners. RELC: A Journal of Language Teaching and Research, 42(2), 155-166. http://dx.doi.org/10.1177/0033688211407295

Wiebe, J., Wilson, T., \& Cardie, C. (2005). Annotating expressions of opinions and emotions in language. Language Resources and Evaluation, 39(2-3), 165-210. http://dx.doi.org/10.1007/s10579-005-7880-9

Yao, X. (2000). An Introduction to Confucianism. Cambridge: Cambridge University Press.

\section{Copyrights}

Copyright for this article is retained by the author(s), with first publication rights granted to the journal.

This is an open-access article distributed under the terms and conditions of the Creative Commons Attribution license (http://creativecommons.org/licenses/by/3.0/). 